\title{
Comparison of Associating factors of Dental Caries in urban and rural children in Jaipur, (Raj) India."
}

\author{
${ }^{1}$ Dr. Rashmi Gupta, ${ }^{2}$ Dr. Kusum Lata Gaur, ${ }^{3}$ Dr. Akhil Kumar Sharma, \\ ${ }^{4}$ Dr. Sumbul Zafer, ${ }^{5}$ Dr. Suresh Kewalramani, \\ ${ }^{1}$ Senior Demonstrator, ${ }^{2}$ Professor, ${ }^{3}$ Dentist, ${ }^{4}$ Dentist, ${ }^{5}$ Assistant Professor \\ ${ }^{1,2,5}$ Department of Community Medicine, SMS Medical College, Jaipur (Raj.) India \\ ${ }^{3}$ Pearl Dental Clinic, G12 Balaji Tower II, Vidyadhar Nagar, Jaipur (Raj.) India) \\ ${ }^{4}$ NIMS Medical College, Jaipur (Raj.) India)
}

\begin{abstract}
Research Question: Comparison of Associating factors of Dental Caries in urban and rural children in Jaipur, (Raj) India.

Methodology: A cross-sectional observational study was carried out on 1600 urban and 1600 rural school children of Jaipur in year 2011. Two blocks for urban areas and two Panchayat Samities for rural areas were selected randomly for the study. Socio-demographic data were collected from parents of children and thorough dental check-up was arranged by a dentist for these children. Children with Carries were identified. Data in details were collected as per pre-designed proforma. Data collected were analysed and inferred with chi-square test.

Result: $37.66 \%$ of children were diagnosed as having dental carries. Dental carries was significantly $(P<0.001)$ lesser in rural areas $(27.94 \%)$ than in the urban areas $(47.38 \%)$. In urban areas age and socioeconomic status were found more associated $(p<0.001)$ with dental carries than sex, mouth ringing frequency, teeth cleaning material and teeth cleaning frequency $(p<0.05)$. In rural areas age, teeth cleaning material and teeth cleaning frequency were found more associated $(p<0.001)$ with dental carries than mother's education, dentist visit and mouth ringing frequency $(p<0.05)$.

Conclusion: More than one third students were having dental Carries. Urban children were having significantly more dental carries than rural. Age, mouth ringing frequency, teeth cleaning material and teeth cleaning frequency were found associated in urban as well as rural areas. In urban areas sex and socioeconomic status but in rural areas mother's education and dentist visit were different associating factors with dental carries.
\end{abstract}

Key words: Dental carries, Socio-demographic, chi-square Test, P Value

\section{Introduction}

Oral health is fundamental to general health and well being, significantly impacting on quality of life. ${ }^{1}$ The ability to chew and swallow is a critical function required to obtain essential nutrients for the body. ${ }^{2}$ Oral diseases qualify as major public health problems owing to their high prevalence and incidence in all regions of the world

Dental caries has historically been considered the most important global oral health burden. The World Health Organization's 2003 report on oral health provides an overview of global caries epidemiology that confirms its international pandemic distribution. Globally, WHO reports caries prevalence in school-age children at 60-90 percent and is virtually universal among adults in the majority of countries . WHO has observed that developed countries have higher rates of caries experience, while developing countries have lower rates. 1

In India prevalence of dental caries in the age group 12-15 years is 45-55 percent in UP, Delhi and Rajasthan as compared to 40-80 percent in Northern States. ${ }^{2}$ Jain $(1979)^{3}$ at RHTC Naila Jaipur and Broca J.S.et al (1983) ${ }^{4}$ of at Ajmer observed prevalence of dental caries $15.90 \%$ and $30 \%$ respectively. It is the commonest cause for loss of teeth among young school children. ${ }^{5}$

Oral health has not been given sufficient importance in our country; preventive dental care is almost nonexistent in the rural areas and very limited in urban areas. Oral health care in rural areas is limited due to shortage of dental manpower, financial constraints and the lack of perceived need for dental care among rural masses. 6 


\section{Materials and Methods}

The present Cross Sectional Analytic type of Observational study was carried out in year 2010 on 1600 School going children aged 5-16 years from each of urban and rural areas . As per Department of Education, Jaipur District has four urban blocks; namely Jaipur East, Jaipur West, Jhotwara and Sanganer. Out of these Jaipur west and Jhotwara were selected randomly for the study. Likewise the rural area of Jaipur District is constituted by 13 Panchayat Samities, out of that two Amber and Jamwaramgarh were selected randomly for the study.

Sample size: Sample size was calculated 1600 subjects at $95 \%$ confidence limit with $10 \%$ allowable error assuming $20 \%$ prevalence of dental cariies. So for the study purpose 1600 children from schools of rural areas and 1600 children from schools of urban areas was included in study. List of rural and urban schools in the selected area was procured from the office of Deputy Director of Education Department, Jaipur District. Schools were also selected randomly using the simple random technique from the procured list to achieve the desired sample size i.e. 1600 from rural and 1600 from urban areas.

Every Institutional Head of identified school was informed about the purpose and methodology of the study and those who had given consent were given the consent form and proforma for parents. 1st part of the designed proforma consisting general information about the child and his family was given to parents of the child through the respective class teachers. After the forms were duly filled up by the parents of the study subjects, it was subsequently collected from the class teachers. Identified Schools were visited on the mutually pre-decided date and time so as to examine the maximum number of study subjects by a dentist. Children were examined in the school premises at a suitable place in presence of respective class teachers with the subjects seated in ordinary chairs in natural day light for illumination, avoiding direct sunlight.

Finally the screened students were examined thoroughly for dental and periodontal diseases, after reassuring them and making them comfortable and taking all necessary aseptic precautions. Part second of the predesigned proforma was filled after examining each child. The same procedure was in identified schools till the sample size of 1600 students of rural and 1600 students of urban area were achieved. Dentition status and treatment need was assessed using Oral Health Assessment Form 2004 [3] by a dentist. Only relevant information related with periodontal diseases along with general information was collected on predesigned proforma. Data thus collected was compiled, analyzed with Microsoft excel 2007.

\section{Results}

The present study has been designed to compare the associating factors of dental Carries amongst students in 5-16 years of age group studying in elementary schools of rural and urban Jaipur.

Of the total 3200 students (1600 rural and 1600 urban) found in 20 identified schools in the study, dental Carries was found in 1205 (37.66\%) surveyed students.

Present study revealed that rural children had significantly less $(\mathrm{p}<0.001)$ dental Carries than the urban children i.e. $27.94 \% \mathrm{v} / \mathrm{s} 47.38 \%$.

Regarding associated factors in the present study age, mouth ringing frequency, teeth cleaning material and teeth cleaning frequency were found associated with dental carries in urban as well as rural areas.

Further it is revealed that maximum children with carries were found in 8-10 years of age in both urban and rural areas. The difference in proportion in cases of dental caries was found to be highly significant $(\mathrm{P}<$ $0.001)$ in both urban and rural areas.

This study observed that sex was found to be associated $(\mathrm{p}<0.05)$ in urban areas whereas in rural areas it was not $(\mathrm{P}>0.05)$.

In the present study type of family, religion and source of drinking water was not found to be associated $(\mathrm{p}>0.05)$ with dental carries in urban as well as in rural areas.

Regarding socio-economic status, it was found to be associated $(\mathrm{P}<0.001)$ with dental carries in urban areas whereas in rural areas it was not.

Further it was found in this study that Father's and mother's education was found to be associated with dental carries in rural areas but in urban areas it was not. It was observed that as education increases proportion of dental carries cases decreases.

In the present study mouth rinsing was found to be associated with dental carries $(\mathrm{p}<0.05)$ in urban as well as in rural areas.

Type of material used for teeth cleaning and frequency of teeth cleaning were found to be associated with dental carries in both the urban and rural areas. Carries was found maximum in children who did not clean their teeth even once and minimum in children who clean their teeth with tooth paste. More so it was also observed with this study that frequency of teeth cleaning was also associated with dental carries in a manner i.e. as the frequency of teeth cleaning increases dental carries decreases.

In the present study, it was observed that the age, type of teeth cleaning materials used, mouth rinsing and teeth cleaning frequency were associated with dental caries while the type of family, religion, father's 
literacy level, drinking water source and type of food consumed were not associated with dental caries both in the urban and rural belts.

\section{Discussion}

The present study showed that dental caries was present in $37.66 \%$. Studies reported by Jain (1979) ${ }^{3}$ at RHTC Naila Jaipur. Broca J.S.et al (1983) ${ }^{4}$, at Ajmer, K Pandit et al (1986) ${ }^{7}$ at Delhi observed $15.90 \%, 30$ $\%, 33.19 \%$ cases of dental caries respectively; the proportion of the cases were little higher in the present study population i.e. $37 \%$. In contrast to the present study, Dash et al (2002) ${ }^{8}$ at Cuttak, Josh (2003) ${ }^{9}$ at Kerala, Saravanan S et al (2003) ${ }^{10}$ in Pondichery, Dhar V et al (2007) ${ }^{11}$ at Udaipur, Joyson Moses (2011) ${ }^{12}$ have reported higher percentages of dental carries i.e. $64.3 \%, 54.3 \%, 44.4 \%, 46.75 \%$ and $63.83 \%$ respectively. This variation may be due to the diverse dietary factors in different areas, structural defects of teeth, anatomical relationship of teeth, form and shape of teeth and hereditary factors.

In the present study it was observed that $47.38 \%$ of children in the urban area, and $27.94 \%$ in the rural area, had caries i.e. more prevalence in the urban areas than in the rural area. Well supported observations were of Mandal KP (2001). ${ }^{13}$

Difference in proportion dental caries cases according to age of children was found to be highly significant $(\mathrm{P}<0.001)$ and observed that initially it decreases with age after the age of 8 years it decreases as age advances. These finding corresponds with the studies conducted by Dash J.K (2002) ${ }^{8}$ Saravanan S et al (2003) ${ }^{10}$ and Dhar V et al (2007) ${ }^{11}$ who reported that caries experience and occurrence of untreated lesions in permanent teeth with age and oral hygiene status worsens as age advanced. This might be due to more prolonged exposure of teeth to the oral environment.

Sex wise distribution of students according to caries status was not found significant in urban with female predominance but in rural it was not. Similar observations were reported by B.Rai et al (2007) ${ }^{14}$ where females had more caries than males. Broca J.S.(1983) ${ }^{4}$ and Dhar et al (2007) ${ }^{11}$ also reported no statistically significant difference in the caries prevalence between both the sexes.

Although significant association was observed in the distribution of cases according to father's education $(p=0.007)$ but there was no significant association with mother's education $(p=0.368)$. Education has an impact on oral health and their relationship is reciprocal.

Significant difference was found in the distribution of the cases according to the drinking water source of the family $(\mathrm{p}<0.001)$ with lesser cases in ground water consumers than tap water.

Present study showed significant difference in the distribution of the cases according to the type of material used for cleaning of teeth $(\mathrm{p}<0.001)$ with minimum cases in children using tooth paste and maximum cases in children either do not clean their mouth. Almost similar was observed by Girish Parmar (2006-07) 15 who reported lesser cases in children using toothpaste than those who used tooth powder and neem datun in Gujarat. Fluoride, the most common active ingredient in toothpaste prevents carries.

Maximum carries cases in children who do not clean their mouth at all $(49.16 \%)$ and minimum cases in children who clean their teeth more than twice per day $(25 \%)$, this difference of carries cases according to frequency of cleaning was found highly significant $(\mathrm{p}<0.001)$. These findings are in accordance with the findings of K. Pandit et al (1986) ${ }^{7}$ who also reported that prevalence of caries was found to increase significantly in those who do not clean their teeth regularly.

\section{Conclusion}

More than one third students were having dental Carries. Urban children were having significantly more dental carries than rural. Although type of families, religion, father's education, and drinking water source was not associated with dental carries but age, mouth ringing frequency, teeth cleaning material and teeth cleaning frequency were found associated in urban as well as rural areas. In urban areas sex and socio-economic status, in rural areas mother's education and dentist visit were also found to be associated with dental carries.

\section{References}

[1]. BL Edelstein. The Dental Caries Pandemic and Disparities Problem. BMC Oral Health 2006; 6 (Suppl 1) : S2 doi : 10.1186/14726831-6-S1-S2. www.who collab od.mah.se.index.html

[2]. Jain, D.C. An epidemiological study of dental and periodontal disease in a group of villages in the area of rural health training centre, Naila (Jaipur). Thesis submitted for the Degree of Doctor of Medicine (Preventive and Social Medicine), University of Rajasthan, 1979. 
[3]. Broca J.S. et al. A study of health status and morbidity pattern of rural school children in headquarter village Jawaja PHC .Current Medical Practise Vol. 27, No.12 Dec 1983; p 363-371.

[4]. Harshal T Pandve. Recent advances in oral health care in India. 2009; Volume 20 : Issue 1: 129-130

[5]. World Health Organization. Oral Health Surveys - Basic Methods; WHO 2004.

[6]. K. Pandit Periodontal disease and dental caries in primary school children in rural areas of Delhi. Indian Journal of Pediatrics 1986; Vol 53, No. $4: 525-529$

[7]. Dash J.K. et al. Prevalence of dental caries and treatment needs among children of Cuttack (Orissa). J Indian Soc Pedo Prev D ent December 2002; 20 (4) : 139-143

[8]. Jose A. Prevalence of dental health problems among school going children in rural Kerala. J. Indian Soc Pedo Prev Dent. 2003; 21: 147-51.

[9]. Saravanan S et al. Prevalence of dental caries and treatment needs among school going children of Pondicherry, India. Journal of the Indian Society of Pedodontics and Preventive Dentistry, 2003; 21 (1): 1-12.

[10]. Dhar V et al. Prevalence of dental caries and treatment needs in the school going children of rural areas in Udaipur District. J Indian Soc Pedo Prev Dent 2007; $25: 119-121$.

[11]. Joyson Moses. Prevalence Of Dental Caries, Socio-Economic Status And Treatment Needs Among 5 To 15 Year Old School Going Children Of Chidambaram Journal Diagnosticof clinical and research. 2011; vol 5(1): 146-151.

[12]. Mandal K.P. Prevalence and severity of dental caries and treatment needs among population in the Eastern states of India. J Indian Soc Pedo Prev Dent. 2001 Sep; 19 (3) : 85-91.

[13]. B. Rai et al: Dental Caries and Oral Hygiene Status of 8 to 12 Year School Children of Rohtak. The Internet Journal of Dental Science. 2007; Vol. 5 No. 1

[14]. Girish Parmar. A Project Report "Management of dental caries in rural areas of Gujrat through Atraumatic Restorative Tecchnique (ART) 2006-07.

Table no. 1 Comparison of Socio-demographic Factors of Dental Carries in Rural and Urban Children

\begin{tabular}{|c|c|c|c|c|c|}
\hline \multirow[t]{2}{*}{ S. No. } & \multirow[t]{2}{*}{ Variables } & \multicolumn{2}{|c|}{ Rural $(\mathrm{N}=1600)$} & \multicolumn{2}{|c|}{ Urban $(\mathrm{N}=1600)$} \\
\hline & & $\begin{array}{c}\text { With Carries } \\
(n=447)\end{array}$ & $\begin{array}{c}\text { Without carries } \\
(n=1153)\end{array}$ & $\begin{array}{c}\text { With Carries } \\
(n=758)\end{array}$ & $\begin{array}{c}\text { Without carries } \\
(n=842)\end{array}$ \\
\hline & \multicolumn{5}{|l|}{ Age Group } \\
\hline 1 & 5 to 7 & $87(19.46)$ & 192 & $110(14.51)$ & 147 \\
\hline 2 & 8 to 10 & $204(45.64)$ & 338 & $360(47.49)$ & 196 \\
\hline 3 & 11 to 13 & $133(29.75)$ & 540 & $261(34.43)$ & 428 \\
\hline 4 & 14 to 16 & $23(5.15)$ & 83 & $27(3.56)$ & 71 \\
\hline \multicolumn{2}{|c|}{ Chi-square Test at DF } & \multicolumn{2}{|c|}{58.186 at 3 DF $\quad \mathbf{P}<\mathbf{0 . 0 0 1} \mathbf{~ H S}$} & \multicolumn{2}{|c|}{109.826 at $3 \mathrm{DF} \quad \mathbf{P}<\mathbf{0 . 0 0 1} \mathbf{H S}$} \\
\hline & \multicolumn{5}{|l|}{ Sex } \\
\hline & Male & $246(28.81)$ & 608 & $347(44.72)$ & 429 \\
\hline & Female & $201(26.94)$ & 545 & $411(49.88)$ & 413 \\
\hline \multicolumn{2}{|c|}{ Chi-square Test at DF } & \multicolumn{2}{|c|}{0.596 at $1 \mathrm{DF} \quad \mathbf{P}=\mathbf{0 . 4 4 0} \mathbf{N S}$} & \multicolumn{2}{|c|}{4.667 at $1 \mathrm{DF} \mathbf{P}=\mathbf{0 . 0 4 4} \mathbf{S}$} \\
\hline & \multicolumn{5}{|c|}{ Socio-economic status } \\
\hline 1 & Upper & $2(0.45)$ & 12 & $16(2.11)$ & 29 \\
\hline 2 & upper middle & $15(3.36)$ & 68 & $66(8.71)$ & 110 \\
\hline 3 & lower middle & $75(16.78)$ & 196 & $158(20.84)$ & 205 \\
\hline 4 & upper middle & $250(55.93)$ & 615 & $384(50.66)$ & 406 \\
\hline 5 & Lower & $105(23.49)$ & 262 & $134(17.68)$ & 92 \\
\hline \multicolumn{2}{|c|}{ Chi-square Test at DF } & \multicolumn{2}{|c|}{5.800 at 4 DF $\quad \mathbf{P}=\mathbf{0 . 2 1 5} \mathbf{~ N S}$} & \multicolumn{2}{|c|}{24.914 at 3 DF $\mathbf{P}<\mathbf{0 . 0 0 1}$ HS } \\
\hline & \multicolumn{5}{|l|}{ Religion } \\
\hline 1 & Hindu & $432(96.64)$ & 1114 & $695(91.69)$ & 776 \\
\hline 2 & Muslim & $14(3.13)$ & 29 & $50(6.60)$ & 57 \\
\hline 3 & Sikh & 0 & 5 & $6(0.79)$ & 3 \\
\hline 4 & Christians & $1(0.22)$ & 3 & $3(0.40)$ & 4 \\
\hline 5 & Others & 0 & 2 & $4(0.53)$ & 2 \\
\hline \multicolumn{2}{|c|}{ Chi-square Test at DF } & \multicolumn{2}{|c|}{ 3.187 at 4 DF $\quad \mathbf{P}=\mathbf{0 . 5 2 7} \mathbf{N S}$} & \multicolumn{2}{|c|}{2.324 at 3 DF $\mathbf{P}=\mathbf{0 . 6 7 6} \mathbf{~ N S}$} \\
\hline & \multicolumn{5}{|l|}{ Type of Family } \\
\hline 1 & Nuclear & $202(45.19)$ & 524 & $494(65.17)$ & 540 \\
\hline 2 & Joint & $189(42.28)$ & 472 & $198(26.12)$ & 224 \\
\hline 3 & Three generation & $56(12.53)$ & 157 & $66(8.71)$ & 78 \\
\hline \multicolumn{2}{|c|}{ Chi-square Test at DF } & \multicolumn{2}{|c|}{0.433 at 2 DF $\quad \mathbf{P}=\mathbf{0 . 8 0 6} \mathbf{~ N S}$} & \multicolumn{2}{|c|}{0.239 at 2 DF $\mathbf{P}=\mathbf{0 . 8 8 7} \mathbf{~ N S}$} \\
\hline & \multicolumn{5}{|c|}{ Father's education (upto) } \\
\hline 1 & Illitrate & $143 \quad(31.99)$ & 286 & $134(17.68)$ & 249 \\
\hline 2 & Middle & $167(37.36)$ & 453 & $300(39.58)$ & 583 \\
\hline 3 & Higher secondary & $127(28.41)$ & 354 & $269(35.49)$ & 621 \\
\hline 4 & Graduation & $8(1.79)$ & 45 & $43(5.67)$ & 118 \\
\hline
\end{tabular}


Comparison of Associating factors of Dental Caries in urban and rural children in Jaipur, (Raj)

\begin{tabular}{|c|c|c|c|c|c|}
\hline 5 & Post graduation & $2(0.45)$ & 15 & $12(1.580$ & 26 \\
\hline \multicolumn{2}{|c|}{ Chi-square Test at DF } & 13.627 at $4 \mathrm{DF}$ & $P=0.009 S$ & \multicolumn{2}{|c|}{6.460 at $4 \mathrm{DF} \quad \mathbf{P}=\mathbf{0 . 1 6 7} \mathbf{N S}$} \\
\hline & \multicolumn{5}{|c|}{ Mother's education (upto) } \\
\hline 1 & Illitrate & $355(79.42)$ & 803 & $373(49.21)$ & 396 \\
\hline 2 & Middle & $68(15.22)$ & 240 & $266 \quad(35.10)$ & 300 \\
\hline 3 & Higher secondary & $22(4.92)$ & 92 & $107(14.11)$ & 125 \\
\hline 4 & Graduation & $1 \quad(0.22)$ & 6 & $11(1.45)$ & 18 \\
\hline 5 & Post graduation & $1(0.22)$ & 12 & $1(0.13)$ & 3 \\
\hline \multicolumn{2}{|c|}{ Chi-square Test at DF } & 17.025 at $4 \mathrm{DF}$ & $\mathrm{P}=0.002 \mathrm{~S}$ & 2.413 at & $\mathrm{P}=\mathbf{0 . 6 6 0} \mathrm{NS}$ \\
\hline
\end{tabular}

Table no. II Comparison of Socio-demographic Factors of Dental Carries in Rural and Urban Children

\begin{tabular}{|c|c|c|c|c|c|}
\hline \multirow[t]{2}{*}{ S. No. } & \multirow[t]{2}{*}{ Variables } & \multicolumn{2}{|c|}{ Rural (N=1600) } & \multicolumn{2}{|c|}{ Urban $(N=1600)$} \\
\hline & & $\begin{array}{c}\text { With Carries } \\
(n=447)\end{array}$ & $\begin{array}{c}\text { Without carries } \\
(n=1153)\end{array}$ & $\begin{array}{c}\text { With Carries } \\
(n=758)\end{array}$ & $\begin{array}{l}\text { Without carries } \\
(n=842)\end{array}$ \\
\hline & \multicolumn{5}{|c|}{ Mouth Rinsing Frequency } \\
\hline 1 & Never & $220(49.22)$ & 463 & $140(18.47)$ & 120 \\
\hline 2 & Sometime & $204(45.64)$ & 626 & $527(69.53)$ & 590 \\
\hline 3 & Always after meals & $23(5.15)$ & 64 & $91(12.01)$ & 132 \\
\hline \multicolumn{2}{|c|}{ Chi-square Test at DF } & \multicolumn{2}{|c|}{10.945 at 2 DF $\mathbf{P}=\mathbf{0 . 0 0 4} \mathbf{S}$} & \multicolumn{2}{|c|}{8.243 at $2 \mathrm{DF} \quad \mathbf{P}=\mathbf{0 . 0 1 6} \mathbf{S}$} \\
\hline & \multicolumn{5}{|c|}{ Teeth Cleaning Frequency } \\
\hline 1 & Zero & $73(16.33)$ & 94 & $44(5.80)$ & 27 \\
\hline 2 & $<1$ & $34(7.61)$ & 54 & $29(3.83)$ & 21 \\
\hline 3 & Once & $246(55.03)$ & 676 & $455(60.03)$ & 507 \\
\hline 4 & Twice & $80 \quad(17.90)$ & 274 & $212(27.97)$ & 262 \\
\hline 5 & $>$ Twice & $14(3.13)$ & 55 & $18(2.37)$ & 25 \\
\hline \multicolumn{2}{|c|}{ Chi-square Test at DF } & \multicolumn{2}{|c|}{33.385 at $4 \mathrm{DF} \quad \mathbf{P}<\mathbf{0 . 0 0 1} \mathbf{H S}$} & \multicolumn{2}{|c|}{10.193 at 4 DF $\mathbf{P}=\mathbf{0 . 0 3 7} \mathbf{S}$} \\
\hline & \multicolumn{5}{|c|}{ Type of Teeth Cleaning Material used } \\
\hline 1 & Fingers & $42(9.40)$ & 94 & $53(6.99)$ & 59 \\
\hline 2 & Tooth Paste & $229(51.23)$ & 693 & $551(72.69)$ & 640 \\
\hline 3 & Tooth powder & $30(6.71)$ & 95 & $99(13.06)$ & 92 \\
\hline 4 & Datun & $60(13.42)$ & 153 & $8(1.06)$ & 19 \\
\hline 5 & Charcoal with finger & $13(2.91)$ & 24 & $3(0.40)$ & 5 \\
\hline 6 & Don’t Clean everyday & $73(16.33)$ & 94 & $44(5.08)$ & 27 \\
\hline \multicolumn{2}{|c|}{ Chi-square Test at DF } & \multicolumn{2}{|c|}{27.550 at 5 DF $\mathbf{P}<\mathbf{0 . 0 0 1} \mathbf{~ H S}$} & \multicolumn{2}{|c|}{11.903 at 5 DF $\mathbf{P}=\mathbf{0 . 0 3 8} \mathbf{S}$} \\
\hline
\end{tabular}

Table III Associating factors of Dental Carries in Rural and Urban Children

\begin{tabular}{|c|c|c|c|c|c|}
\hline \multirow[t]{2}{*}{ S. No. } & \multirow[t]{2}{*}{ Variables } & \multicolumn{2}{|l|}{ Rural Area } & \multicolumn{2}{|l|}{ Urban Area } \\
\hline & & P Value & Level of Significance & P Value & $\begin{array}{l}\text { Level of } \\
\text { Significance }\end{array}$ \\
\hline 1 & Age & $\mathrm{P}<0.001$ & $\mathrm{HS}$ & $\mathrm{P}<0.001$ & $\mathrm{HS}$ \\
\hline 3 & Type of Family & $\mathrm{P}=0.806$ & NS & $\mathrm{P}=0.887$ & NS \\
\hline 4 & Religion & $\mathrm{P}=0.527$ & NS & $\mathrm{P}=0.676$ & NS \\
\hline 5 & Father's Education & $\mathrm{P}=0.564$ & NS & $\mathrm{P}=0.683$ & $\mathrm{NS}$ \\
\hline 7 & Socio-economic Status & $\mathrm{P}=0.215$ & NS & $\mathrm{P}<0.001$ & $\mathrm{HS}$ \\
\hline 8 & Drinking Water Source & $\mathrm{P}=0.953$ & NS & $\mathrm{P}=0.882$ & NS \\
\hline 9 & Type of Food Consumed & $\mathrm{P}=0.738$ & NS & $\mathrm{P}=0.095$ & NS \\
\hline 10 & Dentist's Visit & $\mathrm{P}=0.015$ & $\mathrm{~S}$ & $\mathrm{P}=0.9$ & NS \\
\hline 11 & BMI & $\mathrm{P}=0.015$ & $\mathrm{~S}$ & $\mathrm{P}=0.420$ & NS \\
\hline 12 & Mouth Rinsing Frequency & $\mathrm{P}=0.004$ & $\mathrm{~S}$ & $\mathrm{P}=0.016$ & $\mathrm{~S}$ \\
\hline 2 & Sex & $\mathrm{P}=0.44$ & NS & $\mathrm{P}=0.044$ & $\mathrm{~S}$ \\
\hline 3 & Type of Family & $\mathrm{P}=0.806$ & NS & $\mathrm{P}=0.887$ & NS \\
\hline 4 & Religion & $\mathrm{P}=0.527$ & NS & $\mathrm{P}=0.676$ & NS \\
\hline 5 & Father's Education & $\mathrm{P}=0.564$ & NS & $\mathrm{P}=0.683$ & $\mathrm{NS}$ \\
\hline 6 & Mother's Education & $\mathrm{P}=0.005$ & $\mathrm{~S}$ & $\mathrm{P}=0.686$ & $\mathrm{NS}$ \\
\hline 7 & Socio-economic Status & $\mathrm{P}=0.215$ & NS & $\mathrm{P}<0.001$ & HS \\
\hline 8 & Drinking Water Source & $\mathrm{P}=0.953$ & NS & $\mathrm{P}=0.882$ & NS \\
\hline
\end{tabular}


Comparison of Associating factors of Dental Caries in urban and rural children in Jaipur, (Raj)

\begin{tabular}{|c|l|c|c|c|c|}
\hline 9 & Type of Food Consumed & $\mathrm{P}=0.738$ & $\mathrm{NS}$ & $\mathrm{P}=0.095$ & NS \\
\hline 10 & Dentist's Visit & $\mathrm{P}=0.015$ & $\mathrm{~S}$ & $\mathrm{P}=0.9$ & NS \\
\hline 11 & BMI & $\mathrm{P}=0.015$ & $\mathrm{~S}$ & $\mathrm{P}=0.420$ & $\mathrm{NS}$ \\
\hline 12 & Mouth Rinsing Frequency & $\mathrm{P}=0.004$ & $\mathrm{~S}$ & $\mathrm{P}=0.016$ & $\mathrm{~S}$ \\
\hline 13 & Teeth Cleaning Materials & $\mathrm{P}<0.001$ & HS & $\mathrm{P}=0.038$ & $\mathrm{~S}$ \\
\hline 14 & Teeth Cleaning Frequency & $\mathrm{P}<0.001$ & HS & $\mathrm{P}=0.037$ & $\mathrm{~S}$ \\
\hline
\end{tabular}

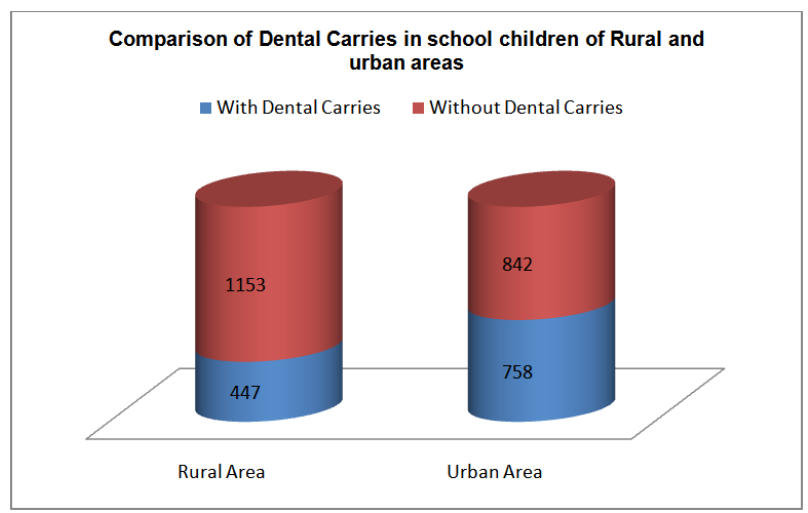

